\title{
Virulência e multiplicação de isolados de Toxoplasma gondii da região central do Rio Grande do Sul ${ }^{1}$
}

\author{
Gustavo C. Cadore ${ }^{2}$, Giovana Camillo ${ }^{2}$, Luis A. Sangioni ${ }^{2}$ e Fernanda S.F. Vogel ${ }^{2 *}$
}

\begin{abstract}
Cadore G.C., Camillo G., Sangioni L.A. \& Vogel F.S.F. 2018. [Virulence and multiplication of Toxoplasma gondii isolates from the central region of Rio Grande do Sul, Brazil.] Virulência e multiplicação de isolados de Toxoplasma gondii da região central do RioGrandedoSul.Pesquisa Veterinária Brasileira38(6):1026-1029.Laboratório deDoenças Parasitárias, Departamento de Medicina Veterinária Preventiva, Universidade Federal de Santa Maria, Av. Roraima 1000, Camobi, Santa Maria, RS 97105-900, Brazil. E-mail: fefevogel@gmail.com

The protozoan Toxoplasma gondii has the ability to infect several animal species, usually causing reproductive disorders. Four different isolates of T. gondii - Pains \#1 (P1), Pains \#2 (P2), Santa Flora \#1 (SF1) and Santa Flora \#306 (SF306) were evaluated with prior genotyping. Their virulence and multiplication capacity were analyzed in vitro (Vero cells) and in vivo (mice). For each isolate, three passages were performed with dose inoculation $1 \times 10^{4}$ tachyzoites at each passage. The mice were daily observed to verify of clinical signs and occurrence of mortality after tachyzoites inoculation. The SF1 isolate and SF306 isolate, presented the highest multiplication of the total tachyzoites number in each of the 3 different passages performed in vitro and in vivo. The initial clinical signs in mice were observed between 5 and 11 days, and occurring mortality between 6 and 15 days, after inoculation. Thus, the parasitic multiplication of theses isolates is similar in vitro and in vivo; different isolates within the same genotype have a similar virulence and the SF1 isolate is the most virulent for mice.
\end{abstract}

INDEX TERMS: Virulence, Toxoplasma gondii, Rio Grande do Sul, toxoplasmosis, Vero cells, tachyzoites, protozoa, genotypes, parasitoses.

RESUMO.- 0 protozoário Toxoplasma gondii possui a capacidade de infectar diversas espécies animais, geralmente causando distúrbios reprodutivos. Quatro diferentes isolados de T. gondii - Pains \#1 (P1), Pains \#2 (P2), Santa Flora \#1 (SF1) e Santa Flora \#306 (SF306) - foram avaliados, após prévia genotipagem. A capacidade de multiplicação e virulência destes isolados foi analisada in vitro (células Vero) e in vivo (camundongos), sendo realizadas 3 passagens para cada isolado em cada modo avaliado, sendo sempre inoculada a dose de $1 \times 10^{4}$ taquizoítos em todas as passagens. Os camundongos eram observados diariamente, quanto à presença de sinais clínicos e ocorrência de mortalidade após inoculação dos taquizoítos. Os isolados SF1 e SF306, foram os que apresentaram maior multiplicação média do número total de taquizoítos em

\footnotetext{
${ }^{1}$ Recebido em 12 de junho de 2017.

Aceito para publicação em 26 de junho de 2017.

${ }^{2}$ Laboratório de Doenças Parasitárias, Departamento de Medicina Veterinária Preventiva, Centro de Ciências Rurais (CCR), Universidade Federal de Santa Maria (UFSM), Santa Maria, Camobi, RS 97105-900, Brasil. *Autor para correspondência: fefevogel@gmail.com
}

cada uma das 3 diferentes passagens realizadas para cada um dos isolados tanto in vitro quanto in vivo. Os primeiros sinais clínicos observados nos camundongos ocorreram entre os dias 5 a 11, após inoculação, com mortalidade acontecendo entre os dias 6 a 15, após inoculação. Assim, a multiplicação parasitária in vitro é semelhante à multiplicação in vivo destes isolados de T. gondii; diferentes isolados com o mesmo genótipo apresentam comportamento de virulência semelhante, caracterizando o isolado SF1 como mais virulento para camundongos.

TERMOS DE INDEXAÇÃO: células Vero, taquizoítos, Virulência, Toxoplasma gondii, protozoário, genótipos, parasitoses, Rio Grande do Sul, toxoplasmose.

\section{INTRODUÇÃO}

Toxoplasma gondii é um protozoário intracelular obrigatório, zoonótico, capaz de infectar mamíferos e aves (Tenter et al. 2000). Nos animais, a doença é caracterizada por distúrbios reprodutivos, gerando perdas econômicas significativas nos 
animais de produção (Garcia et al. 1999, Silva et al. 2003, Pescador et al. 2007, Millar et al. 2008). Felídeos são os únicos hospedeiros definitivos de T.gondii, podendo excretar oocistos no meio ambiente, que servem como fonte de infecção para outros animais (Dubey 2002). Diversas espécies de aves são infectadas pelo parasito, entretanto, na maioria das vezes, a infecção geralmente é assintomática (Dubey 2002, Dubey et al. 2010), porém já foram descritos sinais clínicos nervosos em galinhas caipiras, com posterior identificação de cistos teciduais e taquizoítos no tecido nervoso destes animais (Dubey et al. 2007). Galinhas (Gallus gallus) são aves cosmopolitas e são consideradas importantes hospedeiros intermediários para T. gondii, podendo servir como indicadores de contaminação ambiental, devido a grande exposição aos oocistos (Dubey 2002, 2010) e também devido a significativa detecção de cistos e taquizoítos em tecidos de aves soropositivas (Silva et al. 2003, Lehmann et al. 2006).

Para o diagnóstico de T.gondii, pode ser realizado o bioensaio em camundongos a partir de tecidos de animais com suspeita de infecção (Dubey 2009). Amostras virulentas de T. gondii são letais aos camundongos, induzindo infecção aguda, com possível identificação de taquizoítos nos pulmões, líquido peritoneal e cérebro nos primeiros dias pós-infecção. As amostras avirulentas produzem infecção crônica, com observação de cistos no cérebro e produção e anticorpos específicos (Dubey 2009). Estudos de polimorfismos demonstraram que isolados de T. gondii no Brasil, apresentam uma alta diversidade genética (Ferreira et al. 2001, 2006, Pena et al. 2008) e que este parasito, isolado de tecidos de galinhas no Rio Grande do Sul, apresenta sete genótipos diferentes (Dubey et al. 2007). Com isso, na busca de novas informações sobre a distribuição de T. gondii e da sua diversidade no Brasil, o objetivo deste estudo foi caracterizar a capacidade de multiplicação e a virulência in vitro e in vivo de 4 diferentes isolados de T. gondii de galinhas naturalmente infectadas em área rural da região central do Rio Grande do Sul, Brasil.

\section{MATERIAL E MÉTODOS}

Quatro diferentes isolados de Toxoplasma gondii - Pains \#1 (P1), Pains \#2 (P2), Santa Flora \#1 (SF1) e Santa Flora \#306 (SF306) - obtidos na região central do Rio Grande do Sul, foram avaliados neste estudo. Estas amostras foram obtidas de cérebro e coração de galinhas de vida livre, provenientes da região central do Rio Grande do Sul. A genotipagem destes isolados foi realizada e classificada anteriormente (Camillo 2015).

A avaliação da capacidade de multiplicação in vitro de cada isolado, foi realizada em células Vero (African Green monkey kidney), que são linhagens celulares geralmente utilizadas para manutenção de cultivos de T. gondii (De Meerschman et al. 2002, Saadatnia et al. 2010). As células foram mantidas em frascos para cultivo celular de $25 \mathrm{~cm}^{2}$ (Nunclon Roskilde, Denmark) em meio RPMI-1640 (Gibco, Life Technologies, New York, NY, USA), suplementado com 10\% de soro fetal bovino (Gibco, Life Technologies, New York, NY, USA), incubadas a $37^{\circ} \mathrm{C}$ em atmosfera de $\mathrm{CO}_{2}$ a $5 \%$. Para cada um dos 4 diferentes isolados e em cada passagem celular, as células foram inoculadas sempre com um título final de $1 \times 10^{4}$ taquizoítos, quando o tapete celular apresentava uma confluência de aproximadamente 85\% (Saadatnia et al. 2010). Foram realizadas 3 passagens celulares distintas em cada isolado, sendo os cultivos examinados periodicamente através de microscópio invertido. Quando ocorria destruição máxima do tapete celular (3-5 dias após inoculação), o sobrenadante da cultura era coletado para contagem total de taquizoítos em câmara de Neubauer. Cada experimento foi repetido em triplicata (três cultivos independentes, com três contagens de taquizoítos cada).

Para avaliar a virulência in vivo dos 4 isolados, foram utilizados um total de 48 camundongos Swiss, com 3 semanas de idade. Foram realizadas 3 passagens para cada isolado, com utilização de 4 animais em cada uma delas. Avaliação diária dos sinais clínicos e letalidade nos animais inoculados com os isolados de T. gondii foi realizada, totalizando o uso de 12 camundongos para cada um dos 4 isolados testados. Em cada animal foi inoculado a dose de $1 \times 10^{4}$ taquizoítos, suspendido em 0,2mL de meio RPMI-1640 (Gibco, Life Technologies, New York, NY, USA), injetado pela via intraperitoneal. Após a morte dos animais, os parasitas eram coletados da cavidade peritoneal através de lavagem com 5mL de meio RPMI-1640 (Gibco, Life Technologies, New York, NY, USA), para contagem em câmara de Neubauer.

Todos os procedimentos de manejo e experimentação animais foram realizados de acordo com as recomendações do Comitê Brasileiro de Experimentação Animal (Cobea; Lei no 6.638 de 8 de Maio, 1979) e aprovada pelo Comitê de Ética no Uso de Animais (CEUA) da Universidade Federal de Santa Maria (UFSM), registrado no número CEUA-UFSM 049/2012.

\section{RESULTADOS E DISCUSSÃO}

O número médio de taquizoítos coletados em cada uma das diferentes passagens em células Vero, entre os diferentes isolados de Toxoplasma gondii, está apresentado no Quadro 1. Os isolados SF1 e SF306, foram os que apresentaram maior crescimento médio do número total de taquizoítos em cada uma das 3 diferentes passagens realizadas para cada um dos isolados. A avaliação da capacidade de replicação in vitro e a quantificação do crescimento no número total de taquizoítos é importante tanto para produção e manutenção de estoques (Evans et al. 1999, Mavin et al. 2004), quanto para desenvolvimento ou realização de testes laboratoriais

Quadro 1. Média da produção in vitro de taquizoítos, de quatro diferentes isolados de Toxoplasma gondii inoculados em células da linhagem Vero

\begin{tabular}{|c|c|c|c|}
\hline \multirow[b]{2}{*}{$\begin{array}{c}\text { Isolado } \\
\text { (genótipo) }\end{array}$} & \multirow[b]{2}{*}{ Passagem } & \multicolumn{2}{|c|}{ Taquizoítos $^{\text {a }}$} \\
\hline & & Média coletada & $\begin{array}{c}\text { Índice de } \\
\text { multiplicação }\end{array}$ \\
\hline Pains \#1 & $1^{\mathrm{a}}$ & $1,3 \times 10^{4}$ & $1,3 \mathrm{x}$ \\
\hline \multirow[t]{2}{*}{ (ToxoDB \#11) } & $2^{a}$ & $1,6 \times 10^{4}$ & $1,6 x$ \\
\hline & $3^{a}$ & $2,3 \times 10^{4}$ & $2,3 x$ \\
\hline Pains \#2 & $1^{\mathrm{a}}$ & $1,3 \times 10^{4}$ & $1,3 x$ \\
\hline \multirow[t]{2}{*}{ (ToxoDB \#11) } & $2^{a}$ & $1,7 \times 10^{4}$ & $1,7 x$ \\
\hline & $3^{\mathrm{a}}$ & $2,5 \times 10^{4}$ & $2,5 x$ \\
\hline Santa Flora \#1 & $1^{\mathrm{a}}$ & $1,7 \times 10^{6}$ & $170 x$ \\
\hline \multirow[t]{2}{*}{ (ToxoDB \#64) } & $2^{a}$ & $4,5 \times 10^{5}$ & $45 x$ \\
\hline & $3^{a}$ & $3,7 \times 10^{5}$ & $37 x$ \\
\hline Santa Flora \#306 & $1^{\mathrm{a}}$ & $1,4 \times 10^{6}$ & $140 x$ \\
\hline \multirow[t]{2}{*}{ (ToxoDB \#55) } & $2^{a}$ & $5,6 \times 10^{5}$ & $56 x$ \\
\hline & $3^{\mathrm{a}}$ & $3,7 \times 10^{5}$ & $37 x$ \\
\hline
\end{tabular}

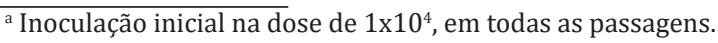


(Joss et al. 1989, Ashburn et al. 2000). Outras finalidades e vantagens da manutenção in vitro de estoques viáveis de taquizoítos de T. gondii, é a redução dos custos de manutenção (Ashburn et al. 2000), bem como evitar ou diminuir o uso de cobaias, por questões éticas, quanto a redução do risco de infecção humana acidental no momento da manipulação ou inoculação de animais.

Os isolados P1 e P2, que possuem genótipo ToxoDB \#11 (Camillo 2015), apresentaram níveis de multiplicação in vitro semelhante, entre cada uma de suas passagens, com ambos possuindo maiores índices de multiplicação na sua terceira passagem (Quadro 1). Já os isolados SF1 possui genótipo ToxoDB \#64; e SF306 com genótipo ToxoDB \#55 (Camillo 2015), mostraram elevados índices de multiplicação de taquizoítos in vitro na primeira passagem. Porém, nas duas passagens subsequentes, ocorreu redução no número médio de taquizoítos viáveis recuperados (Quadro 1). As células de linhagem Vero, são comumente utilizadas para multiplicação e manutenção laboratorial de T. gondii (De Meerschman et al. 2002, Saadatnia et al. 2010), sendo o tipo celular escolhido para avaliação deste trabalho. Taquizoítos de T. gondii, conhecidamente possuem a capacidade de invadir diversos tipos de células nucleadas, em diferentes espécies animais (Miller et al. 1972, Canfield et al. 1990, Inskeep 2nd etal. 1990, Hartley \& Dubey 1991, Dubey et al. 1998, Evans et al. 1999, Chatterton et al. 2002, Lei et al. 2005) e o comportamento referente a quantidade de multiplicação pode estar ligado a uma maior adaptação do tipo de isolado ou tipo celular utilizado para sua manutenção (Diab \& El-Bahy 2008).

Os camundongos inoculados com os 4 diferentes isolados de T. gondii (P1, P2, SF1 e SF306) foram observados diariamente quanto a apresentação dos sinais clínicos de infecção. Os primeiros sinais clínicos foram observados entre 5 a 10 dias após a inoculação (dados não mostrados). Entre os principais sinais clínicos da doença, foram observados: pelos eriçados, lacrimejamento, emagrecimento, diarreia e distensão abdominal. Dependendo da gravidade dos sinais clínicos ou quando os camundongos apresentavam uma condição clínica de doença avançada, estes eram submetidos à eutanásia para coleta de líquido peritoneal. A presença de taquizoítos viáveis de T. gondii obtidos no lavado intraperitoneal, após a morte dos camundongos, foi observado em todos os animais. A média de produção de taquizoítos viáveis encontrados nos camundongos inoculados, em cada uma das três passagens, está demonstrada no Quadro 2.

A mortalidade dos camundongos ocorreu entre o dia 6 (dois animais inoculados com o isolado SF1, na primeira passagem) e o dia 15 (um animal inoculado com o isolado P1, na primeira passagem), após inoculação dos taquizoítos. Os animais inoculados com os isolados P1 e P2 apresentaram os primeiros sinais clínicos de infecção entre os dias 9 a 11 após serem inoculados, com mortalidade ocorrendo entre os dias 12 a 15 após inoculação. Camundongos inoculados com o isolado SF1, demonstraram os primeiros sinais clínicos nos dias 5 e 6 pós-inoculação, com mortalidade sendo observada entre os dias 6 a 9 pós-inoculação. Por fim, os animais inoculados com o isolado SF306, começaram a apresentar sinais clínicos entre os dias 7 a 11 após inoculação e mortalidade de todos os camundongos nos dias 11 e 12 após inoculação. A virulência de T. gondii é bastante variável, sendo que entre
Quadro 2. Média da produção in vivo de taquizoítos, de quatro diferentes isolados de Toxoplasma gondii inoculados em camundongos

\begin{tabular}{|c|c|c|c|}
\hline \multirow[b]{2}{*}{$\begin{array}{c}\text { Isolado } \\
\text { (genótipo) }\end{array}$} & \multirow[b]{2}{*}{ Passagem } & \multicolumn{2}{|c|}{ Taquizoítos $^{\text {a }}$} \\
\hline & & Média coletada & $\begin{array}{c}\text { Índice de } \\
\text { multiplicação }\end{array}$ \\
\hline Pains \#1 & $1^{a}$ & $1 \times 10^{4}$ & $1 \mathrm{x}$ \\
\hline \multirow[t]{2}{*}{ (ToxoDB \#11) } & $2^{a}$ & $1,4 \times 10^{4}$ & $1,4 \mathrm{x}$ \\
\hline & $3^{a}$ & $1 \times 10^{5}$ & $10 x$ \\
\hline Pains \#2 & $1^{\mathrm{a}}$ & $1 \times 10^{5}$ & $10 x$ \\
\hline \multirow[t]{2}{*}{ (ToxoDB \#11) } & $2^{a}$ & $5 \times 10^{5}$ & $50 x$ \\
\hline & $3^{a}$ & $1 \times 10^{5}$ & $10 x$ \\
\hline Santa Flora \#1 & $1^{\mathrm{a}}$ & $1,5 \times 10^{6}$ & $150 x$ \\
\hline \multirow[t]{2}{*}{ (ToxoDB \#64) } & $2^{a}$ & $3,7 \times 10^{5}$ & $37 x$ \\
\hline & $3^{a}$ & $1,6 \times 10^{5}$ & $16 x$ \\
\hline Santa Flora \#306 & $1^{\mathrm{a}}$ & $1,1 \times 10^{5}$ & $110 x$ \\
\hline \multirow[t]{2}{*}{ (ToxoDB \#55) } & $2^{a}$ & $3,7 \times 10^{5}$ & $37 x$ \\
\hline & $3^{a}$ & $1,7 \times 10^{5}$ & $17 x$ \\
\hline
\end{tabular}

a Inoculação inicial na dose de $1 \times 10^{4}$ taquizoítos, em todas as passagens.

estes fatores podem estar relacionados à cepa ou genótipo do isolado, ao estágio evolutivo que se encontra o parasita e também quanto à dose que foi inoculada (Dubey et al. 2004). Neste estudo, como as doses inoculadas $\left(1 \times 10^{4}\right)$ e os estágios evolutivos (taquizoítos), eram os mesmos em todas as passagens, sugere-se que os isolados SF1 e SF306 são os mais virulentos tanto in vitro quanto in vivo, apesar destes aparentemente perderem sua capacidade infectante de forma gradativa (Quadros 1 e 2).

O genótipo ToxoDB \#11, que foi encontrado nos isolados P1 e P2, apresentaram características de virulência semelhante tanto in vivo quanto in vitro, já havia sido descrito causando infecção em gatos e galinhas no Brasil (Dubey et al. 2004, 2008) e em galinhas na Argentina (Rajendran et al. 2012). O genótipo ToxoDB \#55, observado no isolado SF306, também foi anteriormente descrito em gatos no Brasil (Pena et al. 2006), tendo demonstrado uma elevada virulência quando inoculado em camundongos, com altos índices de mortalidade (Pena et al. 2008), igualmente como descrito neste estudo. O isolado SF1, que possui genótipo ToxoDB \#64, também já foi descrito anteriormente em galinhas no Brasil (Dubey et al. 2008). O SF1 foi o isolado de T. gondii que apresentou maior virulência entre os demais testados neste estudo, pois apresentou elevados índices de produção de taquizoítos, com mortalidade dos camundongos inoculados ocorrendo logo aos 6 dias após receberem o inóculo inicial.

\section{CONCLUSÕES}

Baseado nos resultados obtidos foi verificado um comportamento de multiplicação parasitária in vitro semelhante com a multiplicação in vivo entre os isolados de Toxoplasma gondii testados.

Também ficou demonstrado que diferentes isolados, mas que possuem o mesmo genótipo, apresentam comportamento de virulência semelhante, sendo que o genótipo ToxoDB \#64 encontrado no isolado SF1, foi o mais virulento para camundongos, quando comparado entre os demais testados. 


\section{REFERÊNCIAS}

Ashburn D., Evans R., Chatterton J.M., Joss A.W. \& Ho-Yen D.0. 2000. Toxoplasma dye test using cell culture derived tachyzoites. J. Clin. Pathol. 53(8):630-633. http://dx.doi.org/10.1136/jcp.53.8.630. PMid:11002769.

Camillo G. 2015. Toxoplasma gondii em galinhas domésticas: epidemiologia, isolamento e caracterização molecular. Tese de Doutorado, Universidade Federal de Santa Maria, Camobi, RS. 88p.

Canfield P.J., Hartley W.J. \& Dubey J.P. 1990. Lesions of toxoplasmosis in Australian marsupials. J. Comp. Pathol. 103(2):159-167. http://dx.doi. org/10.1016/S0021-9975(08)80172-7. PMid:2246391.

Chatterton J.M., Evans R., Ashburn D., Joss A.W. \& Ho-Yen D.0. 2002. Toxoplasma gondii in vitro culture for experimentation. J. Microbioiol. Methods 51(3):331-335. http://dx.doi.org/10.1016/S0167-7012(02)00101-X. PMid:12223293.

De Meerschman F., Rettigner C., Focant C., Boreux R., Pinset C., Leclipteux T. \& Lossona B. 2002. Use of a serum-free medium to produce in vitro Neospora caninum and Toxoplasma gondii tachyzoites on Vero cells. Vet. Res. 33(2):159-168. http://dx.doi.org/10.1051/vetres:2002004. PMid:11944805.

Diab M.R. \& El-Bahy M.M. 2008. Toxoplasma gondii: virulence of tachyzoites in serum free media at different temperatures. Exp. Parasitol. 118(1):7579. http://dx.doi.org/10.1016/j.exppara.2007.06.009. PMid:17904554.

Dubey J.P. 2002. A review of toxoplasmosis in wild birds. Vet. Parasitol. 106(2):121-153. http://dx.doi.org/10.1016/S0304-4017(02)00034-1. PMid:12031816.

Dubey J.P. 2009. Toxoplasmosis of Animals and Humans. 2nd ed. CRC Press, Boca Raton, p.1-318. http://dx.doi.org/10.1201/9781420092370.

Dubey J.P. 2010. Toxoplasma gondii infections in chickens (Gallus domesticus): prevalence, clinical disease, diagnosis and public health significance. Zoonoses Public Health 57(1):60-73. http://dx.doi.org/10.1111/j.18632378.2009.01274.x. PMid:19744305.

Dubey J.P., Lindsay D.S. \& Speer C.A. 1998. Structure of Toxoplasma gondii tachyzoites, bradyzoites and sporozoites and biology and development of tissue cysts. Clin. Microbiol. Rev. 11(2):267-299. PMid:9564564.

Dubey J.P., Navarro I.T., Sreekumar C., Dahl E., Freire R.L., Kawabata H.H., Vianna M.C.B., Kwok O.C.H., Shen S.K., Thulliez P. \& Lehmann T. 2004. Toxoplasma gondii infections in cats from Paraná, Brazil: seroprevalence, tissue distribution, and biologic and genetic characterization of isolates. J. Parasit. 90(4):721-726. http://dx.doi.org/10.1645/GE-382R. PMid:15359466.

Dubey J.P., Sundar N., Gennari S.M., Minervino A.H., Farias N.A., Ruas J.L., Santos T.R., Cavalcante G.T., Kwok O.C. \& Su C. 2007. Biologic and genetic comparison of Toxoplasma gondii isolates in free-range chickens from the northern Pará state and the southern state Rio Grande do Sul, Brazil revealed highly diverse and distinct parasite populations. Vet. Parasitol. 143(2):182188. http://dx.doi.org/10.1016/j.vetpar.2006.08.024. PMid:16982151.

Dubey J.P., Velmurugan G.V., Chockalingam A., Pena H.F.J., Oliveira L.N., Leifer C.A., Gennari S.M., Oliveira L.M.G.B. \& Su C. 2008. Genetic diversity of Toxoplasma gondii isolates from chickens from Brazil. Vet. Parasit. 157(3/4):299-305. http://dx.doi.org/10.1016/j.vetpar.2008.07.036. PMid:18804329.

Dubey J.P., Rajendran C., Costa D.G., Ferreira L.R., Kwok O.C., Qu D., Su C., Marvulo M.F., Alves L.C., Mota R.A. \& Silva J.C. 2010. New Toxoplasma gondii genotypes isolated from free-range chickens from the Fernando de Noronha, Brazil: unexpected findings. J. Parasitol. 96(4):709-712. http:// dx.doi.org/10.1645/GE-2425.1. PMid:20486738.

Evans R., Chatterton J.M., Ashburn D., Joss A.W. \& Ho-Yen D.0. 1999. Cell culture system for continuous production of Toxoplasma gondii tachyzoites. Eur. J. Clin. Microbiol. Infect. Dis. 18(12):879-884. http://dx.doi.org/10.1007/ s100960050423. PMid:10691199.

Ferreira A.M., Martins M.S. \& Vitor R.W.A. 2001. Virulence for BALB/c mice and antigenic diversity of eight Toxoplasma gondii strains isolated from animals and humans in Brazil. Parasite 8(2):99-105. http://dx.doi. org/10.1051/parasite/2001082099. PMid:11474987.

Ferreira A.M., Vitor R.W.A., Gazzinelli R.T. \& Melo M.N. 2006. Genetic analysis of natural recombinant Brazilian Toxoplasma gondii strains by multilocus
PCR-RFLP. Infect. Genet. Evol. 6(1):22-31. http://dx.doi.org/10.1016/j. meegid.2004.12.004. PMid:16376837.

Garcia J.L., Navarro I.T., Ogawa L. \& Oliveira R.C. 1999. Soroprevalência do Toxoplasma gondii, em suínos, bovinos, ovinos e eqüinos, e sua correlação com humanos, felinos e caninos, oriundos de propriedades rurais do norte do Paraná, Brasil. Ciência Rural 29(1):91-97. http://dx.doi.org/10.1590/ S0103-84781999000100017.

Hartley W.J. \& Dubey J.P. 1991. Fatal toxoplasmosis in some native Australian birds. J. Vet. Diagn. Invest. 3(2):167-169. http://dx.doi. org/10.1177/104063879100300213. PMid:1892936.

Inskeep 2nd W., Gardiner C.H., Harris R.K., Dubey J.P. \& Goldston R.T. 1990. Toxoplasmosis in Atlantic bottle-nosed dolphins (Tursiops truncatus). J. Wildl. Dis. 26(3):377-382. http://dx.doi.org/10.7589/0090-3558-26.3.377. PMid:2388360.

Joss A.W., Skinner L.J., Chatterton J.M., Cubie H.A., Pryde J.F. \& Campbell J.D. 1989. Toxoplasmosis: effectiveness of enzyme immunoassay screening. Med. Lab. Sci. 46(2):107-112. PMid:2593770.

Lehmann T., Marcet P.L., Graham D.H., Dahl E.R. \& Dubey J.P. 2006. Globalization and the population structure of Toxoplasma gondii. Proc. Natl Acad. Sci. 103(30):11423-11428. http://dx.doi.org/10.1073/pnas.0601438103. PMid:16849431.

Lei Y., Davey M. \& Ellis J.T. 2005. Attachment and invasion of Toxoplasma gondii and Neospora caninum to epithelial and fibroblast cell lines in vitro. Parasitology 131(5):583-590. http://dx.doi.org/10.1017/ S0031182005008310. PMid:16255816.

Mavin S., Joss A.W., Ball J. \& Ho-Yen D.0. 2004. Do Toxoplasma gondii RH strain tachyzoites evolve during continuous passage? J. Clin. Pathol. 57(6):609611. http://dx.doi.org/10.1136/jcp.2003.013763. PMid:15166265.

Millar P.R., Daguer H., Vicente R.T., Costa T., Sobreiro L.G. \& Amendoeira M.R.R. 2008. Toxoplasma gondii: estudo soro-epidemiológico de suínos da região Sudoeste do Estado do Paraná. Pesq. Vet. Bras. 28(1):15-18. http://dx.doi. org/10.1590/S0100-736X2008000100002.

Miller N.L., Frenkel J.K. \& Dubey J.P. 1972. Oral infections with Toxoplasma cysts and oocysts in felines, other mammals, and in birds. J. Parasitol. 58(5):928-937. http://dx.doi.org/10.2307/3286588. PMid:5078599.

Pena H.F.J., Soares R.M., Amaku M., Dubey J.P. \& Gennari S.M. 2006. Toxoplasma gondii infection in cats from São Paulo state, Brazil: seroprevalence, oocyst shedding, isolation in mice, and biologic and molecular characterization. Res. Vet. Sci. 81(1):58-67. http://dx.doi.org/10.1016/j.rvsc.2005.09.007. PMid:16289158.

Pena H.F.J., Gennari S.M., Dubey J.P. \& Su C. 2008. Population structure and mouse virulence of Toxoplasma gondii in Brazil. Int. J. Parasitol. 38(5):561569. http://dx.doi.org/10.1016/j.ijpara.2007.09.004. PMid:17963770.

Pescador C.A., Oliveira E.C., Pedroso P.M.O., Bandarra P.M., Okuda L.H., Corbellini L.G. \& Driemeier D. 2007. Perdas reprodutivas associadas com infecção por Toxoplasma gondii em caprinos no sul do Brasil. Pesq. Vet. Bras 27(4):167-171. http://dx.doi.org/10.1590/S0100-736X2007000400007.

Rajendran C., Su C. \& Dubey J.P. 2012. Molecular genotyping of Toxoplasma gondii from Central and South America revealed high diversity within and between populations. Infect. Genet. Evol. 12(2):359-368. http://dx.doi. org/10.1016/j.meegid.2011.12.010. PMid:22226702.

Saadatnia G., Haj Ghani H., Khoo B.Y., Maimunah A. \& Rahmah N. 2010. Optimization of Toxoplasma gondii cultivation in VERO cell line. Trop. Biomed. 27(1):125-130. PMid:20562822.

Silva D.S., Bahia-Oliveira L.M.G., Shen S.K., Kwok O.C.H., Lehman T. \& Dubey J.P. 2003. Prevalence of Toxoplasma gondii in chickens from an area in southern Brazil highly endemic to humans. J. Parasitol. 89(2):394-396. http://dx.doi.org/10.1645/0022-3395(2003)089[0394:POTGIC]2.0. CO;2. PMid:12760664.

Tenter A.M., Heckeroth A.R. \& Weiss L.M. 2000. Toxoplasma gondii: from animals to humans. Int. J. Parasitol. 30(12/13):1217-1258. http://dx.doi. org/10.1016/S0020-7519(00)00124-7. PMid:11113252. 